NBER WORKING PAPER SERIES

\title{
UNTANGLING SEARCHABLE AND EXPERIENTIAL QUALITY RESPONSES TO COUNTERFEITS
}

\author{
Yi Qian \\ Qiang Gong \\ Yuxin Chen \\ Working Paper 18784 \\ http://www.nber.org/papers/w18784
}

\author{
NATIONAL BUREAU OF ECONOMIC RESEARCH \\ 1050 Massachusetts Avenue \\ Cambridge, MA 02138 \\ February 2013
}

Yi Qian is Assistant Professor of Marketing and Yuxin Chen is the Polks Bros. Professor in Retailing, both at the Kellogg School of Management at Northwestern University, 2001 Sheridan Road, Evanston, IL 60208. Qiang Gong is Associate Professor at the Southwestern University of Finance and Economics, Guanghua Building, 55 Guanghuacun Road, Chengdu, Sichuan Province, P.R.China. Please send correspondences to yiqian@kellogg.northwestern.edu, (847)491-7113. The authors are grateful to Philippe Aghion, Eric Anderson, Kevin Bryan, Richard Caves, Anne Coughlan, Josh Lerner, Debu Purohit, Jagmohan Raju, K. Sudhir, and Miguel Villas-Boas for helpful advice and comments. Yi also gratefully acknowledges co-operation from the Chinese Quality and Technology Supervision Bureau (QTSB) and the companies she interviewed and surveyed. The results in this paper do not necessarily represent the views of QTSB or the views of the National Bureau of Economic Research.

At least one co-author has disclosed a financial relationship of potential relevance for this research. Further information is available online at http://www.nber.org/papers/w18784.ack

NBER working papers are circulated for discussion and comment purposes. They have not been peerreviewed or been subject to the review by the NBER Board of Directors that accompanies official NBER publications.

(C) 2013 by Yi Qian, Qiang Gong, and Yuxin Chen. All rights reserved. Short sections of text, not to exceed two paragraphs, may be quoted without explicit permission provided that full credit, including (c) notice, is given to the source. 
Untangling Searchable and Experiential Quality Responses to Counterfeits

Yi Qian, Qiang Gong, and Yuxin Chen

NBER Working Paper No. 18784

February 2013

JEL No. K42,O31,O34

\begin{abstract}
In this paper, we untangle the searchable and experiential dimensions of quality responses to entry by counterfeiters in emerging markets with weak intellectual property rights. Our theoretical framework analyzes the market equilibria under competition with non-deceptive counterfeiting and deceptive counterfeiting, respectively, as well as under monopoly branding. A key theoretical prediction is that emerging markets can be self-corrective with respect to counterfeiting issues in the following sense: First, counterfeiters could earn positive profits by pooling with authentic brands only when consumers have good faith in the market (believe in a low probability that any product is a counterfeit). When the proportion of counterfeits in the market exceeds a cutoff value, brands would invest in self-differentiation from the competitive fringe counterfeiters. Second, to attain a separating equilibrium with counterfeiters, branded incumbents upgrade the searchable quality (e.g. appearance) of their products more and improve the experiential quality (e.g. functionality) less, as compared to monopoly equilibrium. This prediction uncovers the nature of product differentiation in the searchable dimension and helps in analyzing the real-world innovation strategies employed by authentic firms in response to entries by counterfeit entities. In addition, the welfare analyses hint at a non-linear relationship between social welfare and intellectual property enforcement.
\end{abstract}

Yi Qian

Department of Marketing

Kellogg School of Management

Northwestern University

2001 Sheridan Road

Evanston, IL 60208

and NBER

yiqian@kellogg.northwestern.edu

Qiang Gong

Center for Chinese Economic Research

Peking University

Beijing, China

qgongpku@gmail.com
Yuxin Chen

Northwestern University

Department of Marketing

yuxin-chen@kellogg.northwestern.edu 


\section{INTRODUCTION}

Besides rapid growth and industrialization, emerging markets are often characterized by under-development in legal infrastructure. Emerging markets grow fast despite these limitations. Last year, Chinese luxury consumption accounted for USD 12.6 billion, and by 2015, China is expected to top luxury consumption. This study sheds light on some of the self-correcting mechanics of a market in a setting where brands face competition from counterfeiters under weak intellectual property rights, as is common in many of the emerging markets. By providing counterfeit products with an appearance that is similar to that of a brand, counterfeiters can trick consumers into purchasing their products. Even the nondeceptive counterfeits are desired by a large segment of customers in the emerging market. In a 2004 study on global counterfeiting, the World Customs Organization estimated that as much as 512 billion Euros of traded world merchandise may have been counterfeits (Business Week, 2005). The sheer volume of counterfeit merchandise around the world underscores the importance of studying how markets function in the face of counterfeiting, a topic that no multinational corporations operating in emerging markets could avoid. In particular, how should brands design various quality dimensions in response to counterfeiting?

To some extent, the marketing literature has explored the demand of counterfeits (Bloch et al., 1993; Wee et al., 1995; Celso et al. 2007, Commuri 2009, Wilcox et al. 2009, Han et al. 2010), with price, social aspiration, and attitudes toward large branded companies cited as main factors in driving counterfeit demand. On the supply side, several studies have examined piracy effects (Conner and Rumelt, 1991, Sinha et al., 2010, Vernik et al., 2011), legal responsibilities (Olsen and Granzin, 1993), counterfeit impacts in the international trade setting (Grossman and Shapiro 1988, 1989), and firms' internal organizations in complementing weak IPR enforcement (Zhao, 2006 and Qian, 2008). The fact that counterfeiters usually mimic an authentic product's design but offer inferior functional quality has important implications for authentic producers' incentives for innovation and the nature of innovations. Our theoretical framework helps unravel these complexities with intuitive closed-form solutions. While Grossman and Shapiro (1989) primarily define a prestige effect 
as a function of the total sales of the brand (including counterfeits) and one dimensional quality, we decompose quality to a finer level. In addition, we endogenize quality choice.

We build upon a vertical differentiation model (Gabszewicz and Thisse, 1979 and 1980; Shaked and Sutton, 1983) with two dimensions of endogenous quality to analyze the quality and pricing responses to counterfeit entry. Since counterfeiters attempt to copy authentic products and usually produce inferior quality, the competition is actually more vertical in nature. We incorporate two quality dimensions, both vertical in taste. One dimension of quality is observable before purchase, and hence "searchable" (analogous to "search good" as defined by Nelson, 1970). A prominent example of searchable quality is appearance of a product. The other dimension of quality requires experience to know, such as functionality, hence it is "experiential" (analogous to "experience good" as in Nelson, 1970). While Nelson categorizes goods into searchable and experiential, we observe that most products possess a combination of searchable and experiential attributes. This novel model captures the special feature of counterfeits in unbundling searchable quality (e.g., brand name and appearance) and experiential quality (e.g., functionality), and examines the brand's strategies in these two quality dimensions in responses to counterfeiting.

We analyze the market equilibrium under both complete information (in the case of non-deceptive counterfeiting) and asymmetric information (specific to deceptive counterfeiting), and compare equilibrium solutions with the monopoly equilibrium. We take into account asymmetric information by building on the literature of quality uncertainty. Price is the conventional signal for product quality, but Nelson (1974) points out the importance of advertisement as a form of non-price signal for quality. Milgrom and Roberts (1986) argue that prices are better signals for quality than non-price signals (notably advertisements) unless we assume repeated purchases. Moorthy and Srinivasan (1995) propose a money-back guarantee as another effective quality signal. Metrick and Zeckhauser (1999) use a simplified vertical differentiation framework to model competition under asymmetric information. Despite the sophistication of the previous literature, these models only consider a monopolistic market and assume exogenous quality levels. A few exceptions are Moorthy (1988) who examines product and price competition, and Purohit (1994) who models a Counot game 
with endogenous quality. However, their models are confined to a single dimension of quality. There exists a small literature on non-price signaling in nonmonopolistic markets. Hertzendorf and Overgaard (2001) and Fluet and Garella (2002) consider duopolies facing partially uninformed consumers. They show that adjustments along the non-price investments (e.g. advertising and packaging) can be used to signal underlying quality.

Different from these traditional models that consider one pre-determined and often fixed quality for each producer, we introduce two continuous quality variables for the producers. The brand chooses both searchable and experiential quality levels based on which yields more profits, and the counterfeiter also has the liberty to choose quality freely. Unlike a non-deceptive counterfeiter who truthfully reveals both dimensions of quality, deceptive counterfeiters attempt to fool consumers by copying the authentic searchable quality. We incorporate asymmetric information between such counterfeiters and consumers by assuming that a fraction of consumers cannot differentiate counterfeits from authentic products at the same price and searchable quality levels. ${ }^{1}$ We then analyze the quality decisions by producers. This endogenization of qualities helps to explain pricing and quality dynamics in the face of competition.

The key findings among a rich set of results is that emerging markets can be selfcorrective with respect to counterfeit issues in the following sense: First, counterfeiters could earn positive profits by pooling with authentic brands only when consumers have a prior belief on a low probability that any product is a counterfeit. When the proportion of counterfeits in the market exceeds a cutoff value, brands would invest in self-differentiation and profits dissipate for the competitive fringe counterfeiters.

Second, we derive solutions and conditions under which the brand can utilize the two dimensions of quality as key strategic decision variables to combat counterfeits. In the case of non-deceptive counterfeiting, the brand differentiates from counterfeiters by offering a high level of searchable quality if it has a marginal cost advantage over the counterfeiters, while experiential quality would be set at its baseline level. When the brand does not enjoy a cost advantage over counterfeiters, however, no producer would have any incentive

\footnotetext{
${ }^{1}$ The asymmetric information due to status signaling is not dealt with here but is in Qian (2012).
} 
to innovate. Deceptive counterfeiters induce an authentic producer to invest even more in improving searchable quality and less in improving experiential quality, as compared to monopoly equilibrium or competition with non-deceptive counterfeiting. Intuitively, this is because experiential quality is fully appreciated by only the expert consumers (who can tell all quality) at the time of purchase, and the novices cannot correctly infer experiential quality when counterfeits take on the same searchable quality and price as the brand's. The brand therefore has all the more incentives to differentiate from the counterfeiters by raising its searchable quality to an unmatchable level.

While there is no consensus on how entry affects innovation in the economics literature (Purohit 1994, Aghion et al. 2005), marketers often note product differentiation as a practical consequence. Establishing such results in closed-form solution is novel. Our findings yield additional insights into the nature and extent of quality differentiation. Our model aids in understanding the counter-intuitive observation in practice that authentic producers only differentiate in visible quality dimensions and that authentic prices often rise after entry by counterfeiters (Barnett, 2005). In addition, we highlight the strategic nature of searchable quality differentiation and analytically reveal the two uses of searchable quality upgrades in the face of counterfeiting, namely widening the searchable quality gap to alleviate competition and disentangling asymmetric information brought by counterfeiting. Our study provides one of the first analyses on the interesting theoretical finding that searchable quality often times provides signal value for experiential quality and on the conditions under which entry would lead to innovation.

It is worth noting that such innovation responses could generate mixed welfare implications across product categories. In industries where the marginal benefits of searchable quality are high, such as fashion products, the searchable quality innovations would bring welfare gains. However, in other industries where there is little marginal utility associated with searchable quality, such as pharmaceuticals, then such innovation responses are rather wasteful. Our predictions shed new light on the debate in the marketing and economics literature on the relationship between competition and innovation.

We then buttress our main theoretical predictions through business cases across in- 
dustries and empirical settings in Qian (2011). Using panel dataset on the Chinese footwear industry that includes detailed quality dimensions of a representative sample of brands and their corresponding counterfeits, analyses reveal that authentic branded firms invested handsomely on various searchable quality dimensions (shoe style, surface and side materials, etc.), while their shoe bottom and functional quality experienced minor differences, if any at all. Such practices are starting to be adopted by various companies, ranging from Microsoft's software encryptions to the most recent conspicuous CD packaging, and from unique imprints on pharmaceutical pills to holograms on Fendi scarfs (Passariello 2006). All these findings align with our theoretical predictions.

We organize the rest of the paper as follows. We first develop the theoretical model that incorporates two dimensions of quality under competition with asymmetric information. We then proceed to validate the key theoretical predictions. Finally, we conclude by summarizing the managerial insights and contributions.

\section{THEORETICAL FRAMEWORK}

In this section, we first set up the game. We then solve the benchmark case with a monopoly brand before probing into the competitive market equilibria. In particular, we derive the pooling and separating equilibria properties. We refine equilibria with the D1 criterion (Banks and Sobel, 1987). Finally, we end this section with welfare analyses and discussions.

\subsection{Model Set-up}

Extending the traditional vertical differentiation framework to incorporate two dimensions of quality, we characterize a good with an experiential quality (e.g. functionality) index $h_{i}$ and a searchable quality (e.g. appearance) index $s_{i}$, where $i$ indexes good $i$, and each company produces only one good. Experiential quality includes dimensions of quality that are unobserved but can only be inferred. In the data for shoe companies, $h$ includes cushioning effects, frictions, and other shoe functionality. Searchable quality, on the other hand, 
includes dimensions of quality that are searchable or observable at the time of purchase. For instance, $s$ includes the brand name, shoe surface materials, and other appearance characteristics.

There is a continuum of consumers. Each consumer has unit demand $U=V\left(h_{i}, s_{i}, \theta\right)-$ $P_{i}=\theta *\left(h_{i}+s_{i}\right)-P_{i}$ if one unit with quality $\left\{h_{i}, s_{i}\right\}$ is consumed by a consumer with taste $\theta \sim \operatorname{unif}[0,1]$ at the price $P_{i}$, and $U=0$ if the consumer does not buy any unit. All consumers prefer high quality, given the same price. We therefore capture consumer heterogeneity in tastes by $\theta$ : higher $\theta$ indicates more willingness to purchase a given quality. The cumulative distribution function $F(\theta)$ is therefore the fraction of consumers with a taste parameter less than $\theta$. We start with the assumption that the tastes for the two dimensions of quality are collinear because high-income consumers can better afford both dimensions of quality, or because true lovers of the product can better appreciate its finer attributes. ${ }^{2}$ This assumption is similar to that commonly made in the price-discrimination literature: that individuals demand curves do not cross. Relaxing this assumption does not change the predictions qualitatively but only complicates calculations. Results are available upon request.

At first one branded producer leads in the market, and a set of counterfeiters could potentially seek opportunities to enter. To offer a product of quality $q_{i}=\left\{h_{i}, s_{i}\right\}$, the producer $i$ faces a combination of marginal and fixed costs. We model the sunk R\&D cost of experiential quality $h$ (above the baseline level $L$ ) with a function $\eta_{h}(h-L)^{2}$. The sunk cost of searchable quality $s$ above its baseline level $s_{0}$ is analogously defined with $\eta_{s}\left(s-s_{0}\right)^{2}$. The counterfeiters free ride on authentic producer's R\&D and hence incur no sunk costs. We further simplify ${ }^{3}$ without loss of generality that $\eta_{s}=\eta_{h}=\eta$. The marginal costs are:

$$
\beta_{i}(s)=\left\{\begin{array}{cc}
\beta_{s i}^{\prime} & s>s_{0} \\
\beta & s \leq s_{0}
\end{array}, \quad \beta_{i}(h)=\left\{\begin{array}{cc}
\beta_{h i}^{\prime} & h>L \\
\beta & h \leq L
\end{array}\right.\right.
$$

\footnotetext{
${ }^{2}$ Analogously, Grossman and Shapiro (1988) model the utility of a status goods as being derived from its quality and prestige, which positively correlates with quality and negatively relates to total sales. Our model differs from theirs in three important ways: 1 . We disentangle quality into two dimensions; 2 . We endogenize quality and price choices; and 3. We incorporate potential asymmetry in information about quality due to counterfeiting. It is a common phenomenon in emerging markets that consumers are fooled into purchasing counterfeits.

${ }^{3}$ This primarily simplifies the equilibrium solution expressions and comparisons, and results without this simplification is qualitatively the same and available upon request.
} 
The counterfeiters face perfect competition among each other. Without loss of generality, we assume that these counterfeiters are symmetric in their marginal costs. We normalize $\beta_{h i}^{\prime}=\beta_{s a}^{\prime}=\beta$, and $\Delta \beta=\beta_{s l}^{\prime}-\beta_{s a}^{\prime}$ denotes the difference in the marginal costs associated with increasing searchable quality between the counterfeiters (subscript $l$ ) and the brand (subscript $a$ ). Then the set of marginal costs for the brand and counterfeiters are as follows:

$\beta_{a}(s)=\left\{\begin{array}{ll}\beta & s_{a}>s_{0} \\ \beta & s_{a} \leq s_{0}\end{array}, \beta_{a}(h)=\left\{\begin{array}{ll}\beta & h>L \\ \beta & h \leq L\end{array} ; \quad \beta_{l}(s)=\left\{\begin{array}{cc}\beta+\Delta \beta & s_{l}>s_{0} \\ \beta & s_{l} \leq s_{0}\end{array}, \beta_{l}(h)=\left\{\begin{array}{cc}\beta & h_{l}>L \\ \beta & h_{l} \leq L\end{array}\right.\right.\right.\right.$

We model a game with a dominant authentic branded firm and a set of competitivefringe imitators or counterfeiters, which is closest to actual interactions among consumers, authentic and imitative producers. The sequence of events is:

1. An authentic producer chooses her quality, both experiential and searchable dimensions $\left\{h_{a}, s_{a}\right\}$, with the corresponding costs as specified before. She also sets the optimal price $P_{a}$ corresponding to this quality level;

2. Based on the brand's price and quality decisions, counterfeiters decide whether to enter the market and, if so, whether to enter without deception (i.e. revealing the true product source and quality) or with deception (i.e. fooling consumers into thinking they are real) or both;

3. Counterfeiters pick their searchable quality $s_{l}$ and the corresponding price $P_{l}$ for a product with experiential quality $h_{l}$;

4. Each consumer purchases at most one unit of a product.

To solve this game, we first solve for benchmark prices and profits when the authentic firm is a monopoly and when it faces non-deceptive counterfeiters. We then introduce asymmetric information between the counterfeiters and consumers, a unique feature associated with counterfeiters as compared to general entrants. We examine the pooling equilibrium under the constraint that the brand's quality and price choices need to be such that counterfeiters have incentive to pool. We solve for separating equilibrium prices, qualities, and profits when some consumers can be fooled, under the constraint that counterfeiters have no 
incentive to match price and quality with the authentic firm, which is necessary to guarantee separation. Since the authentic firm moves first, his actions will determine whether we are in a pooling or separating equilibrium. Under the D1 criterion, we will prove that there is a unique perfect Bayesian equilibrium. We finally analyze welfare implications of competing with counterfeiters.

\subsection{Monopoly Benchmark}

Let us start with the benchmark scenario where the market has just a monopoly branded producer. Consumers will purchase the authentic product of quality $\left\{h, s_{a}\right\}$ and price $P_{a}$ if they derive positive utility from it. That is, $\theta\left(h+s_{a}\right)-P_{a} \geq 0$, implying that $\theta \geq \frac{P_{a}}{h+s_{a}}$. The market demand for the authentic product is then $1-\frac{P_{a}}{h+s_{a}}$. The authentic producer maximizes profit:

$$
\begin{aligned}
& \max _{h, s_{a}, P_{a}} P_{a} D_{a}\left(s_{a}, h, P_{a}\right)-\left[\beta\left(s_{a}-s_{0}\right)+\beta s_{0}\right] D_{a}\left(s_{a}, h, P_{a}\right) \\
& -\beta h D_{a}\left(s_{a}, h, P_{a}\right)-\eta_{s}\left(s_{a}-s_{0}\right)^{2}-\eta_{h}(h-L)^{2} \\
= & \max _{P_{a}, s_{a}, h}\left[P_{a}-\beta\left(s_{a}-s_{0}\right)-\beta s_{0}-\beta h\right]\left(1-\frac{P_{a}}{s_{a}+h}\right)-\eta\left(s_{a}-s_{0}\right)^{2}-\eta(h-L)^{2}
\end{aligned}
$$

Solving this yields the following

Proposition 1 The optimal choice for the branded monopoly is:

$$
\begin{gathered}
s_{a}^{M}=s_{0}+\frac{(1-\beta)^{2}}{8 \eta} \\
h^{M}=L+\frac{(1-\beta)^{2}}{8 \eta} \\
P_{a}^{M}=\frac{(1+\beta)\left(s_{0}+L\right)}{2}+\frac{(1-\beta)^{2}(1+\beta)}{8 \eta}
\end{gathered}
$$

And the monopolistic profit is :

$$
\pi_{a}^{M}\left(s_{a}^{M}, h^{M}, P_{a}^{M}\right)=\frac{(1-\beta)^{2}\left(s_{0}+L\right)}{4}+\frac{(1-\beta)^{4}}{32 \eta}
$$

Proof: Please see Appendix A.1.

The monopoly brand offers searchable and experiential qualities that are above their baseline levels. The closed-form solutions lend to immediate comparative statics below. 
Corollary $1 \frac{\partial s_{a}^{M}}{\partial \beta}=-\frac{1-\beta}{4 \eta}<0, \frac{\partial s_{a}^{M}}{\partial \eta}=-\frac{(1-\beta)^{2}}{8 \eta^{2}}<0, \frac{\partial h^{M}}{\partial \beta}=-\frac{1-\beta}{4 \eta}<0, \frac{\partial s_{a}^{M}}{\partial \beta}=-\frac{(1-\beta)^{2}}{8 \eta^{2}}<$ $0, \frac{\partial P_{a}^{M}}{\partial \eta}=-\frac{(1-\beta)^{2}(1+\beta)}{8 \eta^{2}}<0$

The comparative statics show that high costs (marginal or fixed) prohibit quality upgrades.

\subsection{Non-deceptive Counterfeits}

We next consider market equilibrium under perfect information. Non-deceptive counterfeits are most common in cases where counterfeiters sell at distinct locations from legitimate sales, notably street corners or small booths in Malls. Non-deceptive counterfeits are present in not only emerging markets but also developed markets, e.g., Canal street in NYC.

In a vertical differentiation framework under complete information, the market naturally segments into three types of consumers. The high-valuation consumers purchase authentic products, the medium-valuation consumers purchase counterfeits, and the lowvaluation consumers purchase none. Hence the demand of the authentic and counterfeit products can be outlined as:

$$
\begin{aligned}
D_{a}\left(s_{a}, h, P_{a}\right) & =1-\frac{P_{a}}{s_{a}+h} \\
D_{l}\left(s_{l}, h_{l}, P_{l}\right) & =\frac{P_{a}}{s_{a}+h}-\frac{P_{a}-P_{l}}{s_{a}-s_{l}+h-h_{l}}
\end{aligned}
$$

With weak intellectual property protection, it is possible for the counterfeiters to fully knockoff the authentic quality levels $\left\{h, s_{a}\right\}$. Therefore, the counterfeiters choose the searchable quality from the interval $\left[s_{0}, s_{a}\right]$ and experiential quality from $[L, h]$. Since the competitivefringe counterfeiters are price takers, their prices are driven to equate marginal costs:

$$
P_{l}=(\beta+\Delta \beta)\left(s_{l}-s_{0}\right)+\beta s_{0}+\beta h_{l}
$$

The brand maximizes profit:

$$
\begin{aligned}
\pi_{a}\left(s_{a}, h, P_{a}\right)= & \max _{P_{a}, s_{a}, h}\left[P_{a}-\beta\left(s_{a}-s_{0}\right)-\beta s_{0}-\beta h\right] D_{a}\left(s_{a}, h, P_{a}\right) \\
& -\eta\left(s_{a}-s_{0}\right)^{2}-\eta(h-L)^{2}
\end{aligned}
$$

The solution depends on the parameter ranges, as discussed below. 
Proposition 2 In a market with complete information and $\Delta \beta \leq 0$, both the authentic producer and the counterfeiters will choose quality $\left\{s_{0}, L\right\}$ and price $P_{a}=P_{l}=\beta s_{0}+\beta L$

Proof: Please see Appendix A.2

This proposition reveals the fascinating intuition that when it takes non-deceptive counterfeiters a lower marginal cost to imitate the authentic searchable quality than the authentic cost, there is no incentive for any producer to offer the bare minimum in both dimensions of quality. The market equilibrium quality will be offered at their baseline levels.

Sometimes the counterfeiters' marginal costs can be higher than the brand's. For instance, elegant appearance of authentic branded shoes requires advanced materials, fine labor, and pattern-press technologies in the production process. Lacking economies of scale and legitimate accesses to technology and knowhow, it is often more costly for counterfeiters to achieve the exact same appearance level as the authentic producer does. Notably, counterfeiters as illegal entities do not have import license to acquire fancy materials (Qian, 2008), and branded companies have strict allocation of raw materials for their subcontracted manufacturers to prevent them from counterfeiting (Zhao, 2006). Counterfeiters usually use inferior materials to mimic the authentic appearance, and it naturally gets harder to do so when the appearance becomes more sophisticated. In light of the fact that the branded producer enjoys economies of scale and designs an appearance level that is hard to imitate, we also consider the case that $\Delta \beta>0$.

Proposition 3 In a market with complete information and $\Delta \beta>0$, the counterfeiters will always choose appearance and functional quality $s_{l}=s_{0}, h_{l}=L$, and price $P_{l}=\beta s_{0}+\beta L$, while the optimal choices for the authentic producer are:

$$
\begin{aligned}
s_{a}^{*} & =s_{0}+\frac{(1-\beta)^{2}}{8 \eta}=s_{a}^{M} \\
h^{*} & =L \\
P_{a}^{*} & =\frac{(1+\beta)(1-\beta)^{2}}{16 \eta}+\beta s_{0}+\beta L
\end{aligned}
$$

And the maximum profit of the brand is :

$$
\pi_{a}^{*}\left(s_{a}, h, P_{a}\right)=\frac{(1-\beta)^{4}}{64 \eta}
$$


Proof: Please see Appendix A.3.

In the case that non-deceptive counterfeiting involves higher marginal cost than the authentic cost for searchable quality, the brand will choose a higher searchable quality (the same as the Monopoly optimum) to differentiate from the counterfeits. The brand offers the baseline level of experiential quality, since the counterfeiters can free rid on the R\&D sunk costs for any functional improvement. The counterfeiter will choose lowest quality level in both dimensions. The equilibrium solutions further give rise to the following comparative statics:

Corollary $2 \frac{\partial s_{a}^{*}}{\partial \beta}=-\frac{1-\beta}{4 \eta}<0, \frac{\partial s_{a}^{*}}{\partial \eta}=-\frac{(1-\beta)^{2}}{8 \eta^{2}}<0, \frac{\partial P_{a}^{*}}{\partial \eta}=-\frac{(1+\beta)(1-\beta)^{2}}{16 \eta^{2}}<0, \frac{\partial\left(P_{a}^{*}-P_{l}^{*}\right)}{\partial \beta}<0$.

The price difference of authentic product over counterfeit decreases when $\beta$ increases. When $\beta$ increases, the counterfeits' price increase, but the price difference of brand over counterfeits decrease. The overall effect is uncertain.

\subsection{Deceptive Counterfeits}

In the previous section, consumers had perfect information on quality. This captures circumstances where non-deceptive counterfeiters reveal their products as different from the authentic ones. In this section, we analyze a market with deceptive counterfeiters, who intends to fool consumers, and compare with the previous equilibria. Asymmetric information is important in the context of counterfeiting, as many articles and news stories reveal how consumers are conned into buying counterfeits. In a Chinese national survey with 30 retailers and 200 consumers (Qian 2012), Some retailers were fooled by the counterfeiters who claimed to be sales force of branded company and who offered huge discounts to fulfill their year-end sales quota. A majority of the consumers at the mall intercepts claim that they cannot tell counterfeits apart, and they usually rely on price or store signals to infer quality and authenticity of the product. 


\subsubsection{Modeling Deception}

While the optimized quality and prices are public information $\left(h, s_{a}, P_{a}, h_{l}, s_{l}, P_{l}\right)$, we assume that a fraction, $\gamma$, of consumers may not be able to tell counterfeits apart from their authentic counterparts at the same price and searchable quality (henceforth shorthanded as "appearance"), at least not until after the purchase. This setup is intuitive because authentic producers tend to provide detailed information about their products in order to build reputation and brand recognition. Counterfeits, on the other hand, mostly try to mimic the appearance of authentic products and misrepresent attributes to extract shortterm windfalls (Qian 2011).

The other $1-\gamma$ fraction of consumers are experts in the product and know exactly the quality of the product they are purchasing. They may purchase counterfeits at a lower price depending on their individual willingness to trade off quality for price (similar to the case with complete information). The uninformed consumers have prior belief on the probability of any product being each type (counterfeit or authentic): $\mu\left(\phi_{c}\right)=\tau$ and $\mu\left(\phi_{a}\right)=1-\tau$. They are drawn uniformly from all consumers in the valuation distribution. ${ }^{4}$ They have experienced various shoes or talked with friends about shoes before and know what the authentic experiential quality should be based on expectations and inferences, although they cannot tell it in practice. They also can calculate the $P_{a}^{s e}, s_{a}^{s e}, s_{0}, s_{a}^{p e}$, and $P_{a}^{p e}$, where the superscripts se,pe denote separating and pooling equilibria, respectively. After observing seller's price and searchable quality, consumers update their beliefs about seller's type. Let $\mu\left(\phi_{i} \mid p, s\right)=1$ denote uninformed consumers' updated beliefs about seller i's type being exactly $\phi=\phi_{i}$.

We handle the technical issue of specifying the out-of-equilibrium beliefs following the prior literature (e.g. Simester 1995, Desai and Srinivasan 1995, Zhao 2000, Feltovich et al 2001, Harbaugh and To 2008, Mayzlin and Shin 2010). We narrow down the set of outof-equilibrium beliefs using an existing refinement. This approach is known for its strength in imposing some structure on the out-of-equilibrium beliefs. That is, the belief that is

\footnotetext{
${ }^{4}$ Relaxing this assumption and drawing them more heavily from the low-valuation consumers would not qualitatively change the results.
} 
consistent with a refinement is more reasonable.

We apply the popular Divinity Criterion (D1) (Banks and Sobel, 1987) to refine the set of perfect Bayesian equilibria. Consider the set of best responses associated with a particular out-of-equilibrium belief. Suppose that the counterfeiter type benefits from the deviation under a bigger set of best responses than the authentic type. Moreover, this is the case for all possible beliefs. D1 then requires that the consumer does not believe that the deviating type is an authentic producer. More generally, suppose that in deviation A1 = $\{p, s\} \neq\left(P^{*}, s^{*}\right)$, the counterfeiter is more likely to yield higher profits than in equilibrium under a bigger set of best responses from the consumer than an authentic producer does. D1 then requires that the consumer does not believe that the product could be authentic. We detail the D1 criterion and its applications in our setting (both separating and pooling equilibria) in Appendix A.14.

The authentic producer maximizes profit:

$$
\max _{P_{a}, s_{a}, h}\left[P_{a}-\beta\left(s_{a}-s_{0}\right)-\beta s_{0}-\beta h\right] D_{a}-\eta\left(s_{a}-s_{0}\right)^{2}-\eta(h-L)^{2}
$$

The counterfeiters can arbitrarily choose appearance quality from $s_{0}$ to $s_{a}$, and functional quality from $L$ to $h$. We assume the counterfeiters choose appearance and functional quality as $\left\{s_{l}, h_{l}\right\}$, where $s_{l}$ is continuous in its domain $\left[s_{0}, s_{a}\right]$ and $h_{l}$ is continuous in its domain $[L, h]$. Then the counterfeiters will again set the price at the marginal cost level due to perfect competition among the fringe players: $P_{l}\left(s_{l}, h_{l}\right)=(\beta+\Delta \beta)\left(s_{l}-s_{0}\right)+\beta s_{0}+\beta h_{l}$

Lemma 1 Under asymmetric information, since consumers cannot observe the functional quality of the product, the counterfeiters will always choose functional quality as $L$.

Proof: Please see Appendix A.4.

In the following sections, we analyze the two types of equilibria: the pooling equilibrium and the separating equilibrium. 


\subsubsection{Pooling Equilibrium}

Our theoretical framework yields insights in the pooling equilibrium where counterfeiters opt into the same price and searchable quality levels as the authentic ones. In this section, we analyze the model to draw out these implications.

Because only $1-\gamma$ fraction of consumers are experts in differentiating authentic products from counterfeits, the other $\gamma$ fraction of consumers will have probability $\tau$ of being conned into purchasing counterfeits ${ }^{5}$. There are now three types of products: authentic branded products, non-deceptive counterfeits that self-differentiate from the authentic products at a lower quality and price, and counterfeits that are indistinguishable from the authentic product in price and appearance (searchable quality). The latter two types of products are both produced by the set of competitive-fringe counterfeiters. Their production capacity is not satiated in either the perfectly competitive low-end market with residual demand or the pooling market with a fixed probability $\tau$ of being purchased by the uninformed consumers. These counterfeiters would then produce both types of products in the pooling equilibrium. They set $\left\{s_{a}, P_{a}\right\}$ for their counterfeit products in a pooling equilibrium and $\left\{s_{l}, P_{l}\right\}$ for the non-deceptive counterfeits.

Expert consumers will always choose authentic products over counterfeits in this pooling equilibrium. The expert consumers who purchase authentic product must derive non-negative utility from it, $V\left(h, s_{a}, \theta\right)-P_{a} \geq 0$, and that utility must exceed their utility derived from a unit of the lower-quality product $V\left(H, s_{a}, x\right)-P_{a} \geq V\left(L, s_{l}, x\right)-P_{l}$. These two conditions imply that their taste parameter $\theta_{a} \geq \max \left(\frac{P_{a}}{h+\alpha s_{a}}, \frac{P_{a}}{h-h_{l}+\left(s_{a}-s_{l}\right)}\right)$. For the non-deceptive counterfeits market to persist, we must have $\frac{P_{a}}{h+s_{a}} \leq \frac{P_{a}}{h-h_{l}+\left(s_{a}-s_{l}\right)}$, implying $\theta_{a} \geq \frac{P_{a}}{h-h_{l}+\left(s_{a}-s_{l}\right)}$.

The novices who purchase any product with appearance $s_{a}$ at price $P_{a}$ must have a positive expected utility, satisfying $(1-\tau) V\left(h, s_{a}, \theta\right)+\tau V\left(s_{l}, s_{a}, \theta\right)-P_{a} \geq 0$ and $(1-$ $\tau) V\left(h, s_{a}, \theta\right)+\tau V\left(s_{l}, s_{a}, \theta\right)-P_{a} \geq V\left(L, s_{l}, \theta\right)-P_{l}$. This implies $\theta \geq \frac{P_{a}}{(1-\tau)\left(h-s_{l}\right)+\alpha\left(s_{a}-s_{l}\right)}$. To

\footnotetext{
${ }^{5} \tau$ is the availability of counterfeit and is a function of government law enforcement. Bearing in mind the risk and penalty of being caught as counterfeits, we assume that there can be at most $\mathrm{N}$ counterfeiters in the market, covering $\tau$ proportion of the market.
} 
simplify the calculation, we define $\Delta s=s_{a}-s_{0}, \Delta h=h-L$.

Lemma 2 The brand faces a demand function:

$$
\begin{aligned}
D_{a}\left(s_{a}, h, P_{a}\right)= & (1-\gamma) D_{i}\left(s_{a}, h, P_{a}\right)+\gamma(1-\tau) D_{u}\left(s_{a}, h, P_{a}\right) \\
= & (1-\gamma)\left(1-\frac{P_{a}-P_{l}}{h-L+s_{a}-s_{0}}\right)+ \\
& \gamma(1-\tau)\left(1-\frac{P_{a}-P_{l}}{(1-\tau)(h-L)+s_{a}-s_{0}}\right)
\end{aligned}
$$

The authentic producer maximizes profits:

$$
\begin{aligned}
\pi_{a}^{p e}\left(s_{a}^{*}, h^{*}, P_{a}^{*}\right)= & \max _{s_{a}, h}\left\{\frac{(1-\gamma \tau)(\Delta s+\Delta h)[(1-\tau) \Delta h+\Delta s]}{2[(1-\tau) \Delta h+(1-\gamma \tau) \Delta s]}-\frac{\beta(\Delta s+\Delta h)}{2}\right\} \\
& \times\left\{\frac{1-\beta-\gamma \tau}{2}-\frac{\beta \gamma \tau}{2[(1-\tau) \Delta h+\Delta s]}\right\}-\eta \Delta s^{2}-\eta \Delta h^{2}
\end{aligned}
$$

Proofs: Please see Appendices A.5 and A.6.

The following set of propositions weave into a fascinating story of the self-corrective mechanism of emerging markets. We detail the predictions and the corresponding intuitions below. The first proposition below shows that asymmetric information aggravates competition and promotes the need to differentiate.

Proposition 4 In the pooling equilibrium, the counterfeiters choose the same searchable quality as the authentic producer and enjoy positive profits. That is, $D_{l}\left(s_{a}^{*}, L, P_{a}^{*}\right)>0$, and $P_{a}^{*}>P_{l}\left(s_{a}^{*}, L\right)$. In addition, $\frac{D_{l}\left(s_{a}^{*}, L, P_{a}^{*}\right)}{D_{l}\left(s_{a}^{*}, L, P_{a}^{*}\right)+D_{a}\left(s_{a}^{*}, h^{*}, P_{a}^{*}\right)}=\tau$.

Proof: Please see Appendix A.7.

In the pooling equilibrium, if attainable by the incentive compatibility constraints of the brand and counterfeiters, the counterfeiters split the market with the brand and earn a positive profit. This is more desirable for counterfeiters than the separating equilibrium, where counterfeiters as fringes compete away the economic rents from the residual demand. We also come to the following conclusions on the comparative statics:

Proposition 5 In a pooling equilibrium with counterfeiters, an authentic producer's optimal strategies $\widetilde{h}, \tilde{s_{a}}, \tilde{P}_{a}$ satisfy $\left.\frac{\partial \pi_{a}^{p e}\left(h, s_{a}, P_{a}\right)}{\partial \gamma}\right|_{h, s_{a}, \tilde{P}_{a}}<0$ and $\left.\frac{\partial \pi_{a}^{p e}\left(h, s_{a}, P_{a}\right)}{\partial \tau}\right|_{h, \tilde{s}_{a}, \tilde{P}_{a}}<0$. With a large enough $\tau$, the brand chooses to separate from counterfeiters. 
Proof: Please see Appendix A.8.

The mathematical derivations confirm the intuition that the authentic producer's profits under pooling equilibrium declines as the proportions of uninformed consumers and counterfeits in the market increase. When there are more uninformed consumers and more counterfeits in the market, the probability that uninformed consumers purchase counterfeits increases. When asymmetric information becomes too severe, the brand has incentives to self-differentiate from the counterfeiters to alleviate the erosion in profits.

Private incentives to compensate for public enforcement surge when counterfeits become very pervasive and when too many consumers cannot tell counterfeits from authentic products. The following Corollary establishes that the authentic producer will upgrade searchable quality to differentiate its product from the counterfeits when the proportion of uninformed consumers is above a threshold level, given any relatively large proportion of counterfeits in the market.

Corollary 3 There exists $\hat{\tau} \in(0,1)$, such that $\forall \tau \in(\hat{\tau}, 1), \exists \gamma^{*}(\tau) \in(0,1)$ so that an authentic producer will choose a separating equilibrium when $\gamma>\gamma^{*}(\tau)$ and prefer pooling equilibrium when $\gamma<\gamma^{*}(\tau)$.

Proof: Please see Appendix A.9.

Analogous to the previous Corollary, the following result illustrates that the authentic producer will choose separating strategies to differentiate its product from the counterfeits when the probability of randomly picking up counterfeits among all products is above a threshold level, given the existence of any relatively large fraction of uninformed consumers in the market.

Corollary 4 There exists $\hat{\gamma} \in(0,1)$, such that $\forall \gamma \in(\hat{\gamma}, 1), \exists \tau^{*}(\gamma) \in(0,1)$ so that an authentic producer will choose a separating equilibrium when $\tau>\tau^{*}(\gamma)$ and prefer pooling equilibrium when $\tau<\tau^{*}(\gamma)$.

Proof: Please see Appendix A.10.

When there are few presence of uninformed consumers or there is a small probability of puchasing counterfeits unknowingly, the authentic producer will opt for the pooling 
equilibrium because the small loss of demand to the counterfeits does not justify the cost for upgrading searchable quality in order to separate from counterfeits.

In sum, it is very interesting to note the self-correction property of the market as analyzed here: when counterfeiting becomes too pervasive and confuses too many consumers in the market, the authentic producer are motivated to upgrade searchable quality and induce counterfeiters into a separating equilibrium, as analyzed in detail in the next sub-section.

\subsubsection{Separating Equilibrium}

If the brand and counterfeiters choose different prices and searchable qualities from each other, then all consumers can tell the products apart based on the model setup, and the resulting prices and profits can be easily solved as in the game with non-deceptive counterfeiting in Section 2.3.

Lemma 3 In separating equilibrium, the counterfeiters will always choose minimum quality $s_{l}=s_{0}, h_{l}=L$, and price $P_{l}=\beta s_{0}+\beta L$. Economic profits dissipate for the competitive fringe counterfeiters.

Proof: Please see Appendix A.11.

The brand and the counterfeiters face the following demand functions, respectively:

$$
\begin{aligned}
& D_{a}\left(s_{a}^{*}, h^{*}\right)=1-2 \beta-\Delta \beta+\sqrt{(\beta+\Delta \beta)(2 \beta+\Delta \beta-1)} \\
& D_{x}\left(s_{l}, h_{l}\right)=\left\{\begin{array}{cc}
2 \beta+\Delta \beta-\sqrt{(\beta+\Delta \beta)(2 \beta+\Delta \beta-1)} & \text { if }\left(s_{l}, h_{l}\right)=\left(s_{0}, L\right) \\
0 & \text { if }\left(s_{l}, h_{l}\right) \neq\left(s_{0}, L\right)
\end{array}\right.
\end{aligned}
$$

The optimal choices for the brand are determined by the following equations:

$$
\begin{aligned}
\Delta \beta\left[1-\frac{(\beta+\Delta \beta)\left(s_{a}^{s e}-s_{0}\right)+\beta\left(h^{s e}-L\right)}{h^{s e}-L+s_{a}^{s e}-s_{0}}\right] & -\Delta \beta\left(s_{a}^{s e}-s_{0}\right) \frac{\Delta \beta\left(h^{s e}-L\right)}{\left(h^{s e}-L+s_{a}^{s e}-s_{0}\right)^{2}} \\
& -2 \eta\left(s_{a}^{s e}-s_{0}\right)=0 \\
\Delta \beta\left(s_{a}^{s e}-s_{0}\right) \frac{\Delta \beta\left(s_{a}^{s e}-s_{0}\right)}{\left(h^{s e}-L+s_{a}^{s e}-s_{0}\right)^{2}} & -2 \eta\left(h^{s e}-L\right)=0
\end{aligned}
$$

We subsequently have the following predications: 
Proposition 6 In the separating equilibrium, there exists $\bar{h}=L+\frac{\Delta \beta^{2}}{2 \eta}$ such that the authentic producer does not improve the experiential quality more than $\bar{h}$. Searchable quality, however, would be improved. In addition, when $\Delta \beta(1-\beta-\Delta \beta)>\frac{(1-\beta)^{2}}{4}$, the brand would upgrade searchable quality even above the monopoly equilibrium level.

Proof: Please see Appendix A.12.

This proposition highlights one of the key findings that counterfeiting could stimulate the brand to offer higher searchable quality but a stagnant experiential quality. Based on the nature of the innovation induced by counterfeits, such innovation could be more valuable for certain industries where searchable quality brings utility in its own right (e.g. fashion) than others where consumer utility is primarily derived from experiential quality (e.g. pharma). We provide empirical support to this prediction based on various cases and a unique panel dataset on the Chinese footwear industry in the next section.

When $\eta_{s}=0$, we obtain the explicit solutions from the brand's profit-maximization problem, and interesting comparative statics follow in the proposition.

\section{Proposition 7}

$$
\begin{aligned}
s_{a}^{\text {se* }}= & s_{0}+\frac{\Delta \beta}{2 \eta \sqrt{2 \beta+\Delta \beta-1}}(\sqrt{\beta+\Delta \beta}-\sqrt{2 \beta+\Delta \beta-1})^{3} \\
h^{\text {se* }}= & L+\frac{\Delta \beta}{2 \eta}(\sqrt{\beta+\Delta \beta}-\sqrt{2 \beta+\Delta \beta-1})^{2} \\
P_{a}^{s e *}= & \beta s_{0}+\beta L+\frac{\Delta \beta}{2 \eta}(\sqrt{\beta+\Delta \beta}-\sqrt{2 \beta+\Delta \beta-1})^{2} \\
& {\left[(2 \beta+\Delta \beta) \sqrt{\frac{\beta+\Delta \beta}{2 \beta+\Delta \beta-1}}-\beta-\Delta \beta\right] }
\end{aligned}
$$

The maximum profit of the authentic producer is:

$$
\pi_{a}^{s e *}\left(s_{a}^{s e}, h^{s e}, P_{a}^{s e}\right)=\frac{\Delta \beta^{2}}{4 \eta}(\sqrt{\beta+\Delta \beta}-\sqrt{2 \beta+\Delta \beta-1})^{4}
$$

The comparative statics are: $\frac{\partial s_{a}^{s e *}}{\partial \Delta \beta}>0, \frac{\partial P_{a}^{s e *}}{\partial \Delta \beta}>0, \frac{\partial P_{a}^{s e *}}{\partial \eta_{h}}<0$

Proof: Please see Appendix A.13.

This proposition reveals the following intuitions: When the marginal cost advantage of the brand over counterfeiters for improving searchable quality $(\Delta \beta)$ increases, the brand would offer a higher searchable quality $\left(s_{a}^{s e *}\right)$ to separate from the counterfeiters, resulting in a 
higher separating equilibrium authentic price $\left(P_{a}^{s e *}\right)$. When fixed $\mathrm{R} \& \mathrm{D}$ cost for improving functional quality $\left(\eta_{h}\right)$ decreases, the brand would improve quality and charge a higher separating price.

In refining the perfect Bayesian equilibria of this game, we have the following

Proposition 8 There is a unique PBE for any parameter values under the D1 Criterion. $\mu_{c}=1 \forall\left(p=P_{a}^{s e}, s=s_{a}^{s e}\right)$ is consistent with D1.

Proof: Please see Appendix A.14.

\subsection{Welfare Implications}

In this section, we calculate the welfare impacts of counterfeiting. Notably, we are interested in deriving the welfare implications of the different market structures.

In the monopoly case, we have $P_{a}^{M}=\frac{(1-\beta)\left(s_{a}^{M}+h^{M}\right)}{2}$, and derive the consumer surplus and social welfare as follows.

$$
\begin{aligned}
C S^{M} & =\int_{\theta}^{1}\left[\theta\left(s_{a}+h\right)-\frac{(1-\beta)\left(s_{a}+h\right)}{2}\right] d \theta=\frac{(1-\beta)^{2}\left(s_{0}+L\right)}{8}+\frac{(1-\beta)^{4}}{32 \eta} \\
S W^{M} & =C S+P S=\frac{3(1-\beta)^{2}\left(s_{0}+L\right)}{8}+\frac{(1-\beta)^{4}}{16 \eta}
\end{aligned}
$$

Under complete information, all producers choose the minimum levels of searchable and experiential quality when $\Delta \beta \leq 0$. So there is no economic profit. $S W^{C}=C S=$ $\int_{\theta}^{1}\left[\theta\left(s_{0}+L\right)-\beta\left(s_{0}+L\right)\right] d \theta=\frac{(1-\beta)^{2}}{2}\left(s_{0}+L\right)$. When $\Delta \beta>0$, however, consumers self select into two segments: the higher-valuation segment purchases authentic product with higher quality and the low-valuation segment purchases counterfeits of the baseline quality levels. The corresponding consumer surpluses and total social welfare are:

$$
\begin{aligned}
C S_{1} & =\int_{\theta}^{1}\left[\theta\left(s_{a}+h\right)-P_{a}\right] d \theta=\frac{3(1-\beta)^{2}\left(s_{0}+L\right)}{8}+\frac{(1-\beta)^{4}}{64 \eta} \\
C S_{2} & =\int_{\underline{\theta}}^{\theta}\left[\theta\left(s_{0}+L\right)-\beta\left(s_{0}+L\right)\right] d \theta=\frac{(1-\beta)^{2}\left(s_{0}+L\right)}{8} \\
S W^{C} & =C S_{1}+C S_{2}+\pi=\frac{(1-\beta)^{2}\left(s_{0}+L\right)}{2}+\frac{(1-\beta)^{4}}{32 \eta}
\end{aligned}
$$


The difference in social welfare between the monopoly and competition under complete information cases is: $\frac{(1-\beta)^{4}}{32 \eta}-\frac{(1-\beta)^{2}\left(s_{0}+L\right)}{8}$. This difference depends on $\eta$ Under asymmetric information, the natural separating equilibrium with informed consumers also results in two segments of consumers.

$$
\begin{aligned}
C S_{1} & =\int_{\theta}^{1}\left[\theta\left(s_{a}+h\right)-P_{a}\right] d \theta=\frac{3(1-\beta)^{2}\left(s_{0}+L\right)}{8}+\frac{(1-\beta)^{4}}{64 \eta} \\
C S_{2} & =\int_{\underline{\theta}}^{\theta}\left[\theta\left(s_{0}+L\right)-P_{x}\right] d \theta=\frac{(1-\beta)^{2}\left(s_{0}+L\right)}{8} \\
S W^{A} & =C S_{1}+C S_{2}+\pi=\frac{(1-\beta)^{2}\left(s_{0}+L\right)}{2}+\frac{(1-\beta)^{4}}{32 \eta}
\end{aligned}
$$

The social welfare turns out to be the same as the complete information case.

Proposition 9 Under symmetric information, the social welfare increases upon the entries of counterfeiters iff $\eta>\frac{(1-\beta)^{4}}{4(1-\beta)^{2}\left(s_{0}+L\right)}$.

Proof: Please see Appendix A.15.

If innovation cost $(\eta)$ is high, it is good to introduce competition to provide more varieties in the product space.

While the social welfare for the separating equilibrium (normalized to be 1 for comparison) and pooling equilibrium with some novices do not have closed-form solutions, we end with some simulations. Figures 3 and 4 reveal that social welfare decline as asymmetric information becomes more rampant in the market (larger $\gamma$ and $\tau$ ).

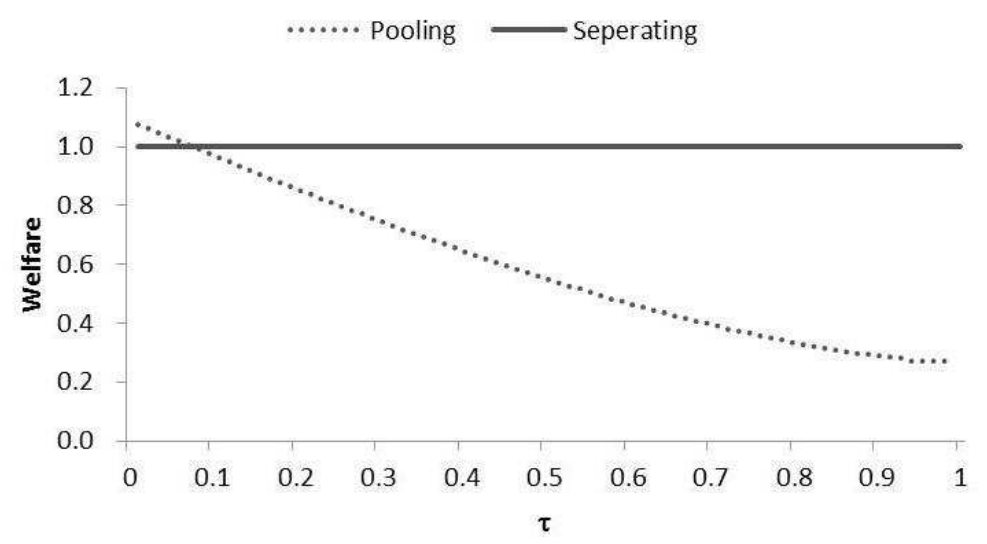

Figure 1: Social Welfare under Pooling and Separating Equilibria as functions of $\tau(s=1)$ 


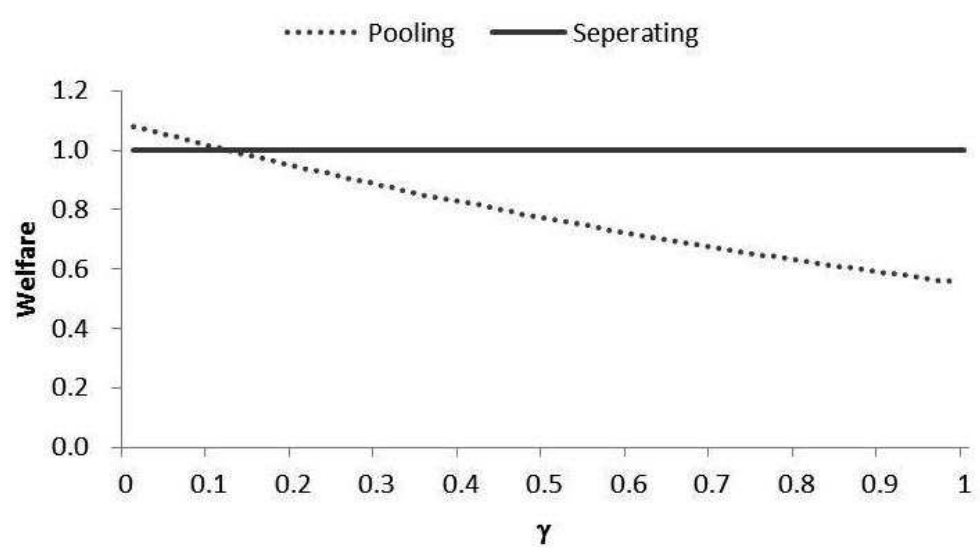

Figure 2: Social Welfare under Pooling and Separating Equilibria as functions of $\gamma(s=1)$

Synthesizing all the results, welfare is likely to be non-linear in government enforcement. Notably, when government enforcement is so strong that there is no counterfeits, monopoly producer surplus is the largest. When public enforcement is medium strong, the brand would choose to pool with moderate amount of counterfeits, where consumer surplus is compromised for the novices. When public enforcement is so weak that counterfeits become rampant in the market, brands innovate to separate from counterfeits, resulting in higher social welfare. Consumers enjoy more product varieties (innovated authentic products and low-quality counterfeits).

\section{Case Validation}

The main theoretical predictions are buttressed through various business cases. As cited in the introduction, many products responded to counterfeit infringements by upgrading searchable quality while the improvement in experiential quality is limited. To note a few examples, In the face of rampant piracy, musicians and recording companies conspicuously package their CDs. Prominent pharmaceutical companies like Abbott and Pfizer adopt unique color, shape, and RFID imprints on each pill to differentiate from counterfeit drug even though the active ingredients of the pill remain the same. Many fashion brands, such as Fendi, adopt visible hologram on their products.

Based on a panel data on branded leather and sport shoes, we provide additional em- 
pirical support to the key proposition that authentic producers have incentives to ameliorate experiential quality upgrades while overinvest in searchable quality in the face of entry by counterfeiters as compared to generic entry (Proposition 1). Furthermore, the easier it is for counterfeiters to imitate authentic searchable quality, the less an authentic producer will upgrade experiential quality (Proposition 2).

Qian (2008) collect panel data on the product price and cost of 31 authentic branded companies operating in China (including multinational and national brands), and the presence of counterfeits of each brand in the years 1993-2004. Based on interviews and analyses on authentic prices and costs, she notes that "the authentic firms did not engage in innovation when there was already significant competition from all the other authentic producers. Innovation occurred and prices jumped only after these authentic brands were infringed upon by counterfeits." (p.1604). Qian (2011) compiles a dataset of different characteristics for each type of shoes listed in the brands' product catalogs, consisting of materials, comfort levels, decorative patterns, support and cushioning features, ventilation, etc. She ran Hedonic regressions of the unit production costs, as provided by the sampled companies, on the corresponding material, machinery, and other characteristics of the shoes, as recorded in the catalogs. Those characteristics together accounted for $90 \%$ of the cost variation on the products. These results lend credibility to the company data.

We study shoe characteristics before and after the brands were infringed by counterfeiters arising from unexpected loosening of government enforcement. Wilcoxon ranksum tests on the set of product characteristics variables pre- and post-entry by counterfeiters provide summary statistics of the innovation patterns. Results (Tables 1 and 2) clearly show that the authentic producers used fancier surface and side materials and improved the shoe appearance tremendously (especially for leather shoes) after counterfeit entry. The equipment and technology were improved significantly as well. There is no matching improvement in the functionality (both at the aggregate level and the detailed-characteristic level): mobility, versatility, having cushioning effects, etc. The overall quality is shown to be better after entry, with an extremely low p-value in the Wilcoxon ranksum test. These findings directly supports the predictions on searchable quality innovations in the Propositions 1 and 2 . 
Insert Tables 1 and 2 about here

\section{CONCLUSION}

Counterfeiting is an unavoidable issue for policy makers and business managers operating in emerging markets. While counterfeit entry is a form of competitive entry, it differs from other regular competition in three key ways. First, counterfeiters attempt to imitate authentic products and free ride on the investments in trademarks and quality by branded companies. Secondly, counterfeiting unbundles searchable quality (e.g., appearance) and experiential quality (e.g., functionality) of a product. Thirdly, counterfeiting has a defining trait of bearing the intent to deceive. Its deceptive nature often gives rise to asymmetric information between the counterfeiters and consumers in transactions. Such asymmetric information could aggravate competition and influence market incentives in nonconventional ways. The media frequently report stories where confused consumers are conned into buying counterfeits. Our model is adept in addressing these scenarios.

The main contribution of this paper is to develop a theoretical model that incorporates all these unique features of counterfeiting competition and to uncover the direction and nature of authentic product innovation in response to counterfeiting. While Nelson (1970) introduced the concepts of searchable and experiential goods in economics, we argue that searchable and experiential dimensions of quality could coexist within the same good. We propose a novel model that include both these quality dimensions to analyze competitive effects by imitators and counterfeiters. In the theoretical literature, this study contributes to offer a tractable theoretical framework to cover two distinct quality dimensions in a vertical differentiation setting and to unveil the entry effects of counterfeits. By examining the equilibrium conditions and allowing the authentic producer to endogenously determine experiential quality and searchable quality as well as prices, we are able to shed new lights on the nature of innovations in different quality dimensions as brand protection strategies. The results therefore have immediate managerial implications. 
In the case of non-deceptive counterfeiting, the brand differentiates from counterfeiters by offering a high level of searchable quality if it has a marginal cost advantage in producing searchable quality over the counterfeiters, while experiential quality would be set at its baseline level. When the brand does not enjoy a cost advantage over counterfeiters, however, no producer would have incentive to innovate and all the quality will be at the bare minimum.

In the case of deceptive counterfieting, our theory predicts a noteworthy phenomenon that market could serves as the invisible hand even for regulating counterfeits. When counterfeiting grows to be too rampant and to fool too many consumers, the market incentives turns from favoring a pooling equilibrium to a separating equilibrium. The authentic brand would invest to innovate and differentiate from the counterfeiters on the searchable quality. In such separating equilibrium, counterfeiting would induce the authentic producer to invest more in product searchable quality (e.g. appearance) and less in experiential quality (e.g., functionality of shoes that are not apparent to consumers at the time of purchase). This could be socially wasteful if searchable quality does not contribute to consumer utility as much as experiential quality does. Theory further shows that the harder it is for counterfeiters to reproduce authentic searchable quality, the more it induces authentic producers to emphasize searchable quality improvements rather than experiential quality improvements.

These predictions are empirically validated by findings on a sample of authentic and counterfeit shoes for 31 brands operating in China. In particular, the branded companies that survived counterfeit infringements all significantly improved shoe surface and side materials and appearance, while functional quality such as sturdiness and flexibility did not witness any significant changes. These innovations pushed up marginal production costs and hence raised authentic prices after their counterfeiters entered the market.

The findings bring to light the nature and extent of product differentiation in the face of counterfeiting, in contrast to a general low-quality competition with perfect information, and provide managerial guidance as to which product attributes to differentiate on. This research enriches a Teecean perspective: a substantial portion of the rents from innovation arise not from technological novelty but from embedding innovation in brands (and other 
searchable quality dimensions) insulated from fringe competition.

This paper is a stepstone in exploring the complex impacts of counterfeits as compared to generic competition. While the current analyses shed light on the key quality and pricing strategies against counterfeits, other strategies (e.g., product line proliferation) and dimensions of asymmetric information and implications can also be associated with counterfeiting. It will be interesting to extend the model to a dynamic multi-period model, where one can study the reputation effects of brands, and explore whether brands would invest in experiential quality in anticipation of future benefits. We are making further attempts to better understand counterfeiters' decisions to enter markets and any potential complementary effects counterfeits could have for authentic products, in line with the analytical framework in Chen and Xie (2007). 


\section{REFERENCES}

Aghion, Philippe, Nick Bloom, Richard Blundell, Rachel Griffith, and Peter Howitt, "Competition and Innovation: An Inverted U Relationship," The Quarterly Journal of Economics, CXX (2) (2005), p. 701-728.

Barnett, Jonathan (2005), "Shopping for Gucci on Canal Street: Reflections on Status Consumption, Intellectual Property and the Incentive Thesis," Virginia Law Review, October.

Banks, J. and J. Sobel (1987), "Selection in Signaling Games," Econometrica 55, 647-662.

Bloch, P.H., Bush, R.F., and Campbell, L. (1993). "Consumer 'Accomplices' in Product Counterfeiting," Journal of Consumer Marketing, 10, p. 27-36.

Bush, R., Bloch, P., and Dawson, S. (1989), "Remedies for Product Counterfeiting," Business Horizons, 32, p. 59-65.

Chen, Yuxin and Jinhong Xie (2007), "Cross-market Network Effect with Asymmetric Customer Loyalty: Implications on Competitive Advantage," Marketing Science, Vol. 26 (Spring): p.52-66

Cho, I. and D. Kreps (1987), "Games and Stable Equilibria," Quarterly Journal of Economics 102, 179-221.

Commuri, Suraj (2009), "The Impact of Counterfeiting on Genuine-Item Consumers Brand Relationships," Journal of Marketing, Vol. 73 (May 2009), 8698.

Conner, K.R. and Rumelt, R.P. (1991), "Software piracy: an analysis of protection strategies," Management Science, Vol. 37, February, pp. 125-39.

Coughlan, Anne, Erin Anderson, Louis Stern, and Adel El-Ansary (2006), Marketing Channels, 7th edition. New Jersey: Prentice-Hall.

Curry, D. J. and P. C. Riesz, "Prices and Price / Quality Relationships: A Longitudinal Analysis," Journal of Marketing, 52 (1988), p. 36-51.

Daughety, A. and J. Reinganum (2008), "Imperfect competition and quality signalling", The RAND Journal of Economics Volume 39, Issue 1, pages 163183, Spring 2008.

Dasgupta, P., Stiglitz, J., (1980). "Industrial structure and the nature of innovative activity." Economic Journal 90 (358), 266293.

Desai, Preyas and Kannan Srinivasan (1995), "Demand Signalling under Unobservable Effort in Franchising: Linear and Non-linear Contracts," Management Science, 41 (10), 16081623.

Desai, Preyas, Oded Koenigsberg, and Devavrat Purohit (2004), "Strategic Decentralization and Channel Coordination," Quantitative Marketing and Economics, 2, p.522.

Feltovich, Nick, Richmond Harbaugh, and Ted To (2002), "Too Cool for School? Signalling and Countersignalling," RAND Journal of Economics, 33 (4), 630-649.

Fluet, C. and P. Garella (2002), "Advertising and prices as signals of quality in a regime of price rivalry," International Journal of Industrial Organization Volume 20, Issue 7, September 2002, pages 907-30. 
Gabszewicz, J. and J.-F. Thisse, "Price Competition, Quality and Income Disparities," Journal of Economic Theory, 20 (1979), p. 340-359.

Gerstner, Eitan and James Hess (1990), "Can Bait and Switch Benefit Consumers?" Marketing Science, Vol. 9, No. 2, Spring 1990, p.114-124.

Greenstein, Shane and Michael Mazzeo (2006), "The Role of Differentiation Strategy in Local Telecommunication Entry and Market Evolution: 1999-2002," Journal of Industrial Economics, LIV (3), September. p.323-350.

Grossman, Gene and Carl Shapiro, "Counterfeit Product Trade," American Economic Review, 78 (1988), p.59-75.

Han, Y., J. Nunes, and X. Drze (2010). "Signaling status with luxury goods: the role of brand prominence." Journal of Marketing, 74, 15-30 July.

Harbaugh, Rick and Theodore To (2008), "False Modesty: When Disclosing Good News Looks Bad," working paper.

Hertzendorf, M. and P. Overgaard (2001) "Price Competition and Advertising Signals: Signaling by Competing Senders", Journal of Economics 85 Management Strategy, Volume 10, Issue 4, pages 621662, Winter 2001.

Lee, T., Wilde, L., (1980). "Market structure and innovation: a reformulation." Quarterly Journal of Economics 94 (2), 429436.

Lichtenstein, D.R., Ridgway, N.M. and Netemeyer, R.G. (1993), "Price perceptions and consumer shopping behavior: a field study," Journal of Marketing Research, Vol. 30, May, pp. 234-45.

Lin, Jessica (2011), Fake Stuff. Routledge, Taylor \& Francis, New York.

Mayzlin, Dina and Jiwoong Shin (2011), "Uninformative Advertising as an Invitation to Search," Marketing Science July-August 2011.

Milgrom, Paul and J. Roberts, "Price and Advertising Signals of Product Quality, "Journal of Political Economy, 94 (1986), p. 796-821.

McGuire, T. and R. Staelin. (1983). "An Industry Equilibrium Analysis of Downstream Vertical Integration," Marketing Science 2(2), p. 239272.

Metrick, Andrew and Richard Zeckhauser, "Price Versus Quantity: Market-Clearing Mechanisms When Consumers are Uncertain about Quality," Journal of Risk and Uncertainty, 17:3 (1999), p. 215-242.

Moorthy, Sridar (1988), "Product and Price Competition in a Duopoly," Marketing Science, Vol.7 (2), p.141-168.

Moorthy, Sridhar and K. Srinivasan (1995), "Signaling Quality with a Money-Back Guarantee: The Role of Transaction Costs," Marketing Science, Volume 14, No. 4, p.442-466.

Nelson, Philip (1970), "Information and Consumer Behavior", Journal of Political Economy, 78(2), p. 311-329.

Nelson, P. (1974), "Advertising as Information," Journal of Political Economy, 82:4, p. 729754.

Olsen, J.E., and Granzin, K.L. (1992), "Gaining Retailers' Assistance in Fighting Counterfeiting: Conceptualization and Empirical Test of a Helping Model," Journal of Retailing, 68, p.90-109. 
Passariello, C. (2006), "Holograms Tell Fake From Fendi", The Wall Street Journal, Feb. 22, 2006, B1, B2.

Pessendorfer, W., "Design Innovation and Fashion Cycles," The American Economic Review, Vol. 85, No. 4, p.771-792.

Purohit, D. (1994), "What Should You Do When Your Competitors Send in the Clones?" Marketing Science, Vol. 13, No. 4 (Autumn, 1994), pp. 392-411.

Qian, Yi (2008), "Impacts of Entry by Counterfeiters," Quarterly Journal of Economics, p. 15771609 .

Qian, Yi (2012), "Brand Management and Strategies Against Counterfeits," forthcoming in Journal of Economics and Management Strategy.

Raustiala, K. and C. Sprigman (2006), "Piracy Paradox," Virginia Law Review, Aug. 2006.

Shaked, A., and John Sutton, "Natural Oligopolies," Econometrica, 51:5 (1983), p.1469-1483.

Simester, Duncan (1995), "Signalling Price Image Using Advertised Prices," Marketing Science, 14 (Summer), 166-188.

Sinha, R., F. Machado, and C. Sellman (2010), "Don't Think Twice, It's All Right: Music Piracy and Pricing in a DRM-Free Environment," forthcoming in Journal of Marketing, Vol. 74, No. 2 : pp. 40-54.

Vernik, D., D. Purohit, and Preyas Desai (2011), "Music Downloads and the Flip Side of Digital Rights Management", Marketing Science, Vol. 30, No. 6, pp. 10111027.

Wee, C., Tan, S., and Cheok, K. (1995), "Non-price Determinants of Intention to Purchase Counterfeit Goods," International Marketing Review, 12, p.1-46.

Wilcox, K., H. Kim, and S. Sen (2009), "Why Do Consumers Buy Counterfeit Luxury Brands?" Journal of Marketing Research, Vol. 46 (April), 24759.

World Customs Organization, "Counterfeiting Congress Calls for Public-private Cooperation,"

http://www.wcoomd.org/ie/En/Press/press.html (May 25, 2004).

Zhao, Hao (2000), "Raising Awareness and Signaling Quality to Uninformed Consumers: A Price-Advertising Model," Marketing Science, Vol. 19, No. 4, Autumn, 2000, p.390396.

Zhao, Minyuan (2006), "Conducting R\&D in Countries with Weak Intellectual Property Rights Protection". Management Science, 56 (7): 118599. 


\section{Table 1. Leather Shoe Quality Changes Before and After Counterfeit Infringement}

Medium Value

(1)
$(2)$

Ranksum Test

(3)

\begin{tabular}{lccc} 
Quality dimensions & Pre-Entry & Post-Entry & p-value \\
\hline Surface Material & Regular cow & Precious cow & $.000^{* * *}$ \\
Side Material & Regular cow & Sheep & $.000^{* * *}$ \\
Bottom Material & Regular & Regular $(5 \%$ cow skin $)$ & .72 \\
Appearance & Fine & Elegant, Patterns & $.000^{* * *}$ \\
Functionality & 6.06 & 6.08 & .83 \\
Workmanship & .93 & .95 & .26 \\
Versatility & .096 & .10 & .77 \\
Cushioning & .096 & .1 & .88 \\
Quality & 18.6 & 22.6 & $.000^{* * *}$ \\
\hline
\end{tabular}

This Table tabulates the Ranksum test statistics for the leather shoe characteristics pre- and postcounterfeit entry. All the characteristics variables are categorical. Surface material includes 14 varieties, ranging from plastic leather to crocodile skin; Side material includes 7 varieties, ranging from plastic leather to baby cow skin; Bottom material includes 5 varieties, ranging from inferior PU to cow skin. The Appearance variable is the sum of the dummies indicating whether a pair of shoes is fine, elegant, and with decorative patterns. Functionality is an aggregate variable for various functional attributes, including adroit (a dummy equals one if a pair of shoes is adroit), absorption (a dummy equals one if a pair of shoes absorbs sweat), athleticfeet (a dummy equals one if a pair of shoes helps treat athletic feet), soft, cushion (a dummy equals one if a pair of shoes has cushion effects), and comfort, sturdy, warm, friction (a dummy equals one if a pair of shoes protects from slippery grounds). Workmanship is a dummy that equals one if a pair of shoes is carefully and finely manufactured. Quality is the sum of all dimensions of shoe characteristics. 


\section{Table 2. Sport Shoe Quality Changes Before and After Counterfeit Infringement}

Medium Value

(1)
Ranksum Test

$(2)$

\begin{tabular}{lccc} 
Quality dimensions & Pre-Entry & Post-Entry & p-value \\
\hline Surface Material & PU; net & Syn.leather;light net & $.000^{* * *}$ \\
Bottom Material & MD & TPR & .229 \\
Air Pumps & none/middle & top/middle/back & $.02^{* *}$ \\
Appearance & Fine & Fine/Elegant & $.09^{*}$ \\
Functionality & 12 & 12 & \\
Workmanship & 1 & 1 & \\
Versatility & 1 & 1 & \\
Supportiveness & 1 & 1 & $.000^{* * *}$ \\
Quality & 21.3 & 24.1 & \\
\hline
\end{tabular}

This Table tabulates the Ranksum test statistics for the authentic sport shoe characteristics pre- and post- counterfeit entry. All the characteristics variables are categorical. Surface and Side material includes 6 varieties, ranging from inferior PU to real leather with materials for nets; Bottom Material includes 4 varieties, ranging from TPU to special rubbe; . The Appearance variable is the sum of the dummies indicating whether a pair of shoes is fine, and elegant. Functionality is an aggregate variable for various functional attributes, including adroit (a dummy equals one if a pair of shoes is adroit), absorption (a dummy equals one if a pair of shoes absorbs sweat), athleticfeet (a dummy equals one if a pair of shoes helps treat athletic feet), soft, cushion (a dummy equals one if a pair of shoes has cushion effects), comfort, sturdy, warm, friction (a dummy equals one if a pair of shoes protects from slippery grounds), lasting (a dummy equals one if a pair of shoes lasts a long time), support (a dummy equals one if a pair of shoes supports the ankle well), and flexibility. Workmanship is a dummy that equals one if a pair of shoes is carefully and finely manufactured. Quality is the sum of all dimensions of shoe characteristics. 